\title{
Assessment of Macular Function by Multifocal Electroretinogram after Intravitreal Injection of Bevacizumab in Diabetic Macular Edema
}

\author{
Yomna Essam ${ }^{1}$, Khalid Ali ${ }^{2}$, Ahmed Elhusseiny ${ }^{3}$, Soha Moussa ${ }^{4}$ \\ ${ }^{1}$ Ophthalmology Resident, Faculty of Medicine, Benha University, Egypt \\ ${ }^{2}$ Professor of Ophthalmology, Faculty of Medicine, Benha University, Egypt \\ ${ }^{3}$ Assistant Professor of Ophthalmology, Faculty of medicine, Benha University, Egypt \\ ${ }^{4}$ Lecturer of ophthalmology, Faculty of medicine, Benha University, Egypt
}

\begin{abstract}
Purpose: To evaluate intravitreal Bevacizumab (IVB) in treatment of diabetic macular edema (DME) using Multifocal Electroretinogram (Mf-ERG). Methods: Twenty eyes of sixteen patients with diffuse and/or focal DME without macular ischemia received primary IVB $(1.25 \mathrm{mg} / 0.1 \mathrm{ml})$. Multifocal electroretinography was done as baseline, 1 week, 2 weeks and 3 weeks post injection. Results: Mean visual acuity improved from $(0.37 \pm 0.23)$ to $(0.42 \pm 0.30), 25 \%$ of patients reported near vision improvement. Central foveal thickness improved significantly from $(375.80 \pm 14.48$ micrometer $(\mu m))$ to $(225.0 \pm 30.08$ um) and parafoveal and perifoveal thickness improved from $(317.00 \pm 36.2 \mu \mathrm{m})$ to $(282.80 \pm 27.97 \mu \mathrm{m})$. At the end of the $3^{\text {rd }}$ week, $P$ wave amplitude improved from (34.64 \pm 9.62 nanovolt per square degree $\left.\left(n V / d_{e g}\right)\right)$ to $\left(44.54 \pm 8.32 n V / d e g_{2}\right), N$ wave amplitude improved from $(0.135 \pm 0.060$ $\left.n V / d e g_{2}\right)$ to $\left(0.299 \pm 0.160 \mathrm{nV} / d^{2} g_{2}\right)$. Conclusion: Intravitreal Bevacizumab resulted in macular function improvement in the study patients with DME, postoperative improvement in visual acuity and decreased retinal thickness confirmed by improvement of $P$ wave and $N$ wave in Mf-ERG.
\end{abstract}

Keywords: Bevacizumab, Multifocal Electroretinography, Diabetic macular edema

\section{Introduction}

Macular edema is defined as an abnormal thickening of the macula associated with the accumulation of excess fluid in the extracellular space of the neurosensory retina. Intracellular edema involving Muller cells has also been observed histopathologically in some cases. ${ }^{(1)}$

Diabetic macular edema results from retinal microvascular changes. Thickening of the basement membrane and reduction in the number of pericytes are believed to lead to increased permeability and incompetence of the retinal vasculature .This compromise of the blood retinal barrier (BRB) leads to the leakage of plasma constituents into the surrounding retina, with subsequent retinal edema. Hypoxia produced by this mechanism can also stimulate the production of vascular endothelial growth factor (VEGF). There is evidence that VEGF is up-regulated in DME and proliferative diabetic retinopathy. ${ }^{(2)}$

Anti-VEGF agents, interfering with a critical stimulus for the development of BRB breakdown, have been investigated in the treatment of DME, as Pegaptanib sodium (Macugen, Eyetech Pfizer), Ranibizumab (Lucentis, Genentech Inc., San Francisco, CA), Bevacizumab (Avastin, Genentech, Inc., South San Francisco, CA) which is a full-length humanized antibody against VEGF. Although bevacizumab is currently approved by FDA (The US Drug Food and Drug Administration) for the treatment of metastatic colorectal cancer, it is widely used as an off-label treatment for neovascular age-related macular degeneration (ARMD) and retinal vascular disorders including retinal vein occlusion and DME. Randomized diabetic retinopathy clinical research network trial (DRCR.net) evaluated short-term effect of intravitreal bevacizumab demonstrating a beneficial action in DME. ${ }^{(3)}$

The Mf-ERG is considered the best electro-functional method to diagnose and monitor macular disorders. It provides a measure of retinal and macular integrity especially when the changes are minimal and dysfunction is localized in a small area. The Mf-ERG reflects the function of a wide part of the posterior pole (40-50 degrees), and the result obtained groups together a set of weak amplitude responses $\left(10^{-9}\right.$ volts $)$ mainly elicited by the first two retinal layers (photoreceptor layer and outer plexiform - bipolar layer). ${ }^{(4)}$

The Mf-ERG examination has proved to be very useful in the preclinical phase but less suitable in the follow up of patients with diabetic retinopathy (DR) after medical intervention or laser surgery, especially in comparison with other methods of examination such as the optical coherence tomography (OCT) and the fundus fluorescein angiography (FFA). However many results are conflicting, also because of the subjects heterogenecity and the differences in the techniques used. ${ }^{(4)}$

\section{Patients and Methods}

Study design

A non-randomized prospective study. 


\section{International Journal of Science and Research (IJSR) \\ ISSN (Online): 2319-7064}

Index Copernicus Value (2013): 6.14 | Impact Factor (2015): 6.391

\section{Setting:}

The study was carried out from April 2014 to June 2015 on twenty eyes of sixteen patient with diffuse and/or focal DME without macular ischemia. All eyes received primary IVB $(1.25 \mathrm{mg} / 0.1 \mathrm{ml})$. The patients were selected from the outpatient ophthalmology clinic of Benha University hospital.

Eligibility for the study:

- Age Eligible for Study: from 40 Years to 70 Years.

- Gender Eligible for Study: Both genders were included.

\section{Inclusion Criteria:}

- Patients with Type II diabetes mellitus with nonproliferative diabetic retinopathy (NPDR) and significant focal or diffuse DME confirmed by FFA and OCT.

- Glucose level must be controlled and evaluated by Glycosylated hemoglobin (HBA1c).

\section{Exclusion criteria}

- Other retinal or macular pathology like ARMD or any occlusive disease affecting retina.

- Optic disc pathology due to chronic glaucoma.

- Patients previously treated with Argon laser.

- Patients with proliferative diabetic retinopathy \pm tractional retinal detachment and vitreoretinal traction.

- Previously treated eyes with intravitreal triamcinolone or any anti-VEGF.

- Patients with chronic renal failure or history of stroke were excluded from the study.

- Patients with media opacity affecting cornea, lens, vitreous that interfere with evaluation of macula by biomicroscopy, OCT or FFA.

\section{Methods}

Before injection complete ophthalmological examination was done for every patient including:

- History taking, duration, and onset of diminution of vision, previous ocular surgery interventions.

- Best corrected visual acuity using decimal. (BCVA)

- Slit lamp biomicroscopy.

- Applanation tonometry.

- FFA was done on Topcon 3D OCT-2000:

- A colored photo of the fundus was taken at first prior to injection. Then, a series of digital photographs were taken after injection of fluorescein.

- Macular OCT:

Macular OCT was done to detect the presence of retinal thickening, cystoid macula edema, hard exudates and vitreoretinal interface and to assess the central foveal thickness (CFT).

Baseline central retinal characteristics were analyzed by OCT through a dilated pupil. The analysis of macular edema (from the central $1 \mathrm{~mm}$ ) were used for macular thickness results.

Line scans: vertical and horizontal $6 \mathrm{~mm}$ line scan passing through the central fovea. The line scan comprises 1024 axial scans. Sixteen scans for 16384 total data points averaged to single scan image.

Central foveal thickness was measured manually in all scans using the caliper tool built in the OCT software and the mean of measured thickness is documented. Retinal thickness was defined as the distance between the inner retinal surface defined as the interface between the dark vitreous and the bright reflection of internal limiting membrane and the outer retinal surface defined as the inner surface of bright retinal pigment epithelium (RPE) /Bruch's membrane interface.

\section{Mf-ERG recording procedure}

We recorded Mf-ERG by using HK Loop electrodes, on the Ronald Consult Super Colour Ganzfield Q450, after 10 minutes of light adaptation and pupil dilation with tropicamide. The stimulus consisted of 61 hexagons, covering $25-30^{\circ}$ of visual field and presented on a 20 inch monitor at a viewing distance of $33 \mathrm{~cm}$. Refractive errors were corrected for the viewing distance. A ground electrode is connected to the forehead. The fellow eye is occluded with light pressure to prevent blinking and the electrical artifacts it can introduce.

The Mf-ERG recordings are performed using the ,standard ${ }^{\text {ee }}$ Mf-ERG visual stimulus. The hexagon areas increased with eccentricity to compensate differences in cone density across the retina (leading to a fourfold size change). Each hexagon was temporally modulated between light and dark (frame rate: $60 \mathrm{~Hz}$; maximum luminance: $120 \mathrm{~cd} \cdot \mathrm{m}^{-2}$ ). Subjects were instructed to fixate a small black cross in the center of the stimulus. Fixation was checked by means of online video monitoring during the 6 minutes lasting recording sessions and high amplitude artifacts were automatically eliminated. To improve fixation stability, sessions were broken into 45 second segments, and eight trials were recorded in total. Signals were amplified with a gain of 100.000 and filtered with a band-pass filter $(5-300 \mathrm{~Hz})$. The surface electrode impedance was less than $10 \mathrm{k} \Omega$. For each hexagon, the amplitude of P1 (defined as the difference between N1 trough and P1 peak) and N1 was calculated, and the implicit time of the P1 component determined from the onset of the stimulus till the peak of the P1 and N1 component.

\section{Data Output}

Average responses were calculated for the fovea which corresponds to hexagon number 31 and for four retinal quadrants as in the (Fig: 1). The view in the printout corresponds to the retinal view. The responses and their measurements are plotted at corresponding retinal locations rather than in visual field orientation. The (Fig: 1) shows the orientation of different group quadrants. Quadrant one corresponds to the upper temporal retina, quadrant two corresponds to the lower temporal retina, quadrant three corresponds to the lower nasal retina and quadrant four corresponds to the upper nasal retina. 


\section{International Journal of Science and Research (IJSR) \\ ISSN (Online): 2319-7064}

Index Copernicus Value (2013): 6.14 | Impact Factor (2015): 6.391

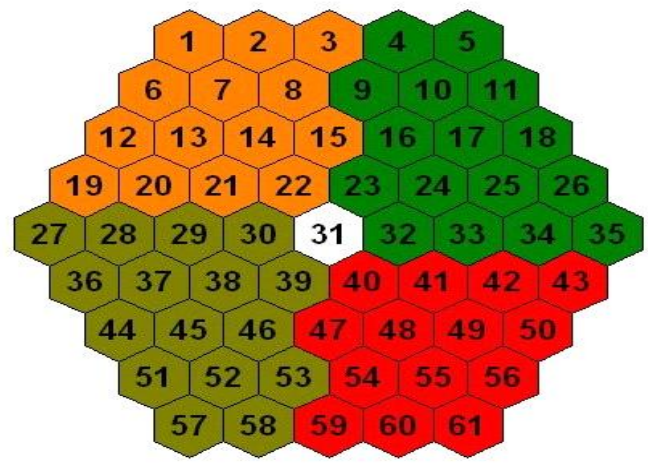

Figure 1: Quadrant orientation: Fovea corresponds to hexagon 31.The optic disc and arcades are outlined.

\section{Treatment Technique}

Informed consent

The patients signed a consent for intervention including: advantages, disadvantages, risks of possible complications especially for the intravitreal injection

\section{Intravitreal bevacizumab injections}

- Intravitreal injections were done in the operating theater under sterile conditions after the pupils were dilated using tropicamide $1 \%$.

- Topical anesthesia with Benoxinate HCL $0.4 \%$ eye drops.

- Ocular surface sterilization with betadine eye drops 5\% and sterile drapes were applied.

- Insertion of an eye lid speculum, $1.25 \mathrm{mg}(0.1 \mathrm{ml})$ bevacizumab was injected through pars plana with a 28 gauge needle through the superotemporal quadrant $4 \mathrm{~mm}$ behind the limbus.

- Central retinal artery perfusion and intraocular pressure (IOP) were assessed just after injection, paracentesis was done if IOP was markedly increased.

- Application of eye ointment (combination of antibiotic and steroid)

- Eye patching by sterile dressing.

- Topical antibiotic moxifloxacin $5 \mathrm{mg} / \mathrm{ml}$ was prescribed for 5 days.

- All complications will be recorded.

\section{Follow up:}

- Day 1, day 3, day 5, 1 week , 2 weeks , 3 weeks.

- Each patient was followed up to detect improvement of the visual acuity and CFT and any complications.

- Follow up was by BCVA, slit lamp examination and biomicroscopy, applanation tonometry, Fundus examination., OCT macular thickness done once post injection, Mf-ERG examinations was carried at 1 week, 2 weeks and 3 weeks post injection.

\section{Data management}

The clinical data were recorded on a report form. These data were tabulated and analyzed using the computer program SPSS (Statistical package for social science) version 16 to obtain. A $\mathrm{P}$ value $<0.05$ was considered statistically significant $(*)$ while $>0.05$ statistically insignificant, $\mathrm{P}$ value $<0.01$ was considered highly significant $(* *)$ in all analyses.

\section{Results}

Sixteen patients with twenty eyes attended the ophthalmic outpatient clinic in the period between April 2014 to June 2015 were selected. They suffered focal or /and diffuse diabetic macular edema without macular ischemia. All eyes received primary IVB $1.25 \mathrm{mg}(0.1 \mathrm{ml})$. They were 8 males, 12 females, their ages ranges from 40-68 years with mean $(54.20 \pm 11.10) 4$ cases were bilateral, 12 cases were unilateral. FFA showed 16 eyes with diffuse diabetic macular edema while 4 eyes with focal diabetic macular edema. Decimal visual acuity ranged between $(0.1-0.9)$ with mean $(0.39 \pm 0.30)$. CMT using OCT was $(289-610 \mu \mathrm{m})$ with mean $(375.80 \pm 124.10)$, parafoveal thickness with OCT was $(249-331 \mu \mathrm{m})$ with mean $(317 \pm 36 \mu \mathrm{m})$. (Table1)

Table 1: Preoperative demographic data and clinical characteristics

\begin{tabular}{|c|c|c|}
\hline Male & $\begin{array}{c}\text { No }(20 \\
\text { eyes })\end{array}$ & $\%$ \\
Female & 8 & 40.0 \\
\hline Age mean \pm SD (range) & $54.2 \pm 11.1(40-68)$ \\
\hline $\begin{array}{c}\text { Right eye } \\
\text { Left eye }\end{array}$ & 8 & 40.0 \\
\hline Hypertension & 12 & 60.0 \\
Present & 4 & 20.0 \\
Absent & 16 & 80.0 \\
\hline FFA & 16 & 80.0 \\
Diffuse edema & 4 & 20.0 \\
\hline Focal macular edema & $0.39 \pm 0.30(0.1-0.9)$ \\
\hline $\begin{array}{c}\text { Decimal visual acuity } \\
\text { mean } \pm \text { SD (range) }\end{array}$ & \multicolumn{3}{|c|}{$610)$} \\
\hline $\begin{array}{c}\text { Central macular OCT thickness } \\
\text { mean } \pm \text { SD (range) }(\mu \mathrm{m})\end{array}$ & $375.80 \pm 124.10(289-$ \\
\hline $\begin{array}{c}\text { Parafoveal and perifoveal OCT } \\
\text { thickness mean } \pm \text { SD (range) }(\mu \mathrm{m})\end{array}$ & \multicolumn{3}{|c|}{$317.00 \pm 36(249-331)$} \\
\hline
\end{tabular}

Visual acuity improved from $(0.37 \pm 0.23)$ preoperative to $(0.42 \pm 0.29)$ at the end of the third week as shown in Table 2 and Figure 2.

Table 2: Differences between preoperative and postoperative BCVA

\begin{tabular}{|c|c|c|c|}
\hline BCVA & $\begin{array}{c}\text { mean } \\
\pm \mathrm{SD}\end{array}$ & $\begin{array}{c}\text { Paired } \\
\text { t test }\end{array}$ & $\begin{array}{c}\mathrm{P} \\
\text { value }\end{array}$ \\
\hline Pre-operative & $0.37 \pm 0.23$ & & \\
\hline $1^{\text {st }}$ week post-operative & $0.42 \pm 0.34$ & 0.921 & 0.369 \\
\hline $2^{\text {nd }}$ week post-operative & $0.40 \pm 0.30$ & 0.657 & 0.519 \\
\hline $3^{\text {rd }}$ week post-operative & $0.42 \pm 0.29$ & 1.07 & 0.297 \\
\hline
\end{tabular}

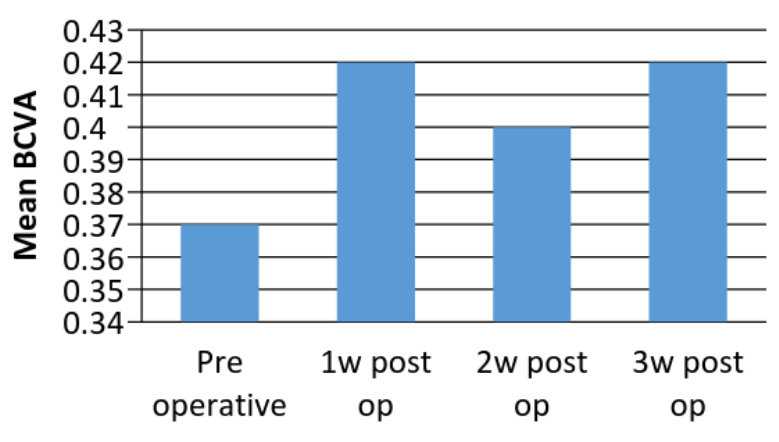

Figure 2: Diagrammatic representation between preoperative and postoperative BCVA difference. 


\section{International Journal of Science and Research (IJSR) \\ ISSN (Online): 2319-7064 \\ Index Copernicus Value (2013): 6.14 | Impact Factor (2015): 6.391}

As regards intraocular pressure there was a little rise of IOP after $1^{\text {st }}$ week with highly significant difference $\mathrm{P}$ value $<$ 0.006 . It returned back to the preoperative level on the third week (Table 3).

Table 3: Differences between preoperative and postoperative IOP

\begin{tabular}{|c|c|c|c|}
\hline IOP & $\begin{array}{c}\text { mean } \pm \text { SD } \\
(\mathrm{mmHg})\end{array}$ & $\begin{array}{c}\text { Paired t } \\
\text { test }\end{array}$ & P value \\
\hline Preoperative & $14.4 \pm 2.95$ & & \\
\hline $1^{\text {st }}$ week post operative & $16.0 \pm 1.300$ & 3.110 & $0.006^{* *}$ \\
\hline $2^{\text {nd }}$ week post operative & $14.0 \pm 0.00$ & 0.607 & 0.551 \\
\hline $3^{\text {rd }}$ week post operative & $14.4 \pm 3.760$ & 0.000 & 1.0 \\
\hline
\end{tabular}

Measurement of CMT using OCT showed statistically significant improvement $\mathrm{P}<0.001$. The CMT decreased from $(375.80 \pm 14.48 \mu \mathrm{m})$ preoperative to $(225.00 \pm 30.08 \mu \mathrm{m})$ postoperative, the parafoveal and perifoveal OCT thickness decreased from $(317.00 \pm 36.20 \mu \mathrm{m})$ preoperative to $(282.80 \pm 27.97 \mu \mathrm{m})$ postoperative as shown in Table 4, Figure 3.

Table 4: Difference between preoperative and postoperative OCT thickness

\begin{tabular}{|c|c|c|c|c|}
\hline & $\begin{array}{c}\text { Pre } \\
\text { mean } \pm \text { SD } \\
(\mu \mathrm{m})\end{array}$ & $\begin{array}{c}\text { Post } \\
\text { mean } \pm \text { SD } \\
(\mu \mathrm{m})\end{array}$ & $\begin{array}{c}\text { Paired } \\
\text { t test }\end{array}$ & P value \\
\hline $\begin{array}{c}\text { Central foveal } \\
\text { OCT thickness }\end{array}$ & $375.80 \pm 14.48$ & $225.00 \pm 30.08$ & 5.38 & $0.001^{* *}$ \\
\hline $\begin{array}{c}\text { Parafoveal and } \\
\text { perifoveal OCT } \\
\text { thickness }\end{array}$ & $317.00 \pm 36.20$ & $282.80 \pm 27.97$ & 6.86 & $0.001^{* *}$ \\
\hline
\end{tabular}

\section{$\mathrm{CMT}$}

Perifoveal \& parafoveal OCT thickness

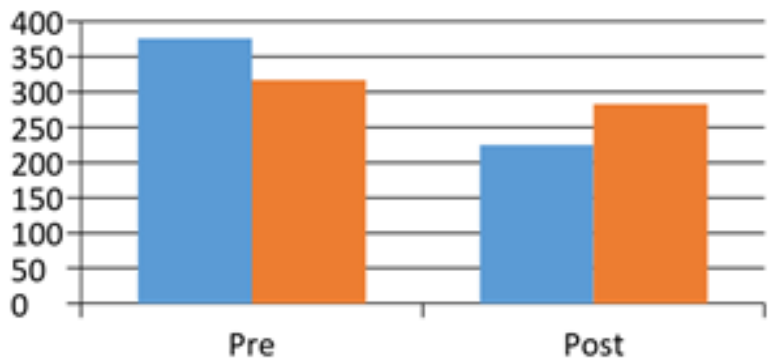

Figure 3: Diagrammatic representation of preoperative and postoperative OCT thickness

Table $5 \&$ Figure 4 showed the comparison of $\mathrm{P}$ wave amplitudes measurement between preoperative and $1^{\text {st }}, 2^{\text {nd }}$, $3^{\text {rd }}$ weeks follow ups. There was increase in $\mathrm{P}$ wave amplitude on $1^{\text {st }}, 2^{\text {nd }}, 3^{\text {rd }}$ weeks with highly significant difference $\mathrm{P}<0.001$.

Table 5: Differences between preoperative and postoperative $\mathrm{P}$ wave amplitude.

\begin{tabular}{|c|c|c|c|}
\hline Amplitude & $\begin{array}{c}\text { mean } \pm \text { SD } \\
(\mathrm{nV} / \mathrm{deg} 2)\end{array}$ & $\begin{array}{c}\text { Paired t } \\
\text { test }\end{array}$ & P value \\
\hline Preoperative & $34.64 \pm 9.62$ & & \\
\hline $1^{\text {st }}$ week post operative & $48.2 \pm 14.49$ & 6.43 & $0.001^{* *}$ \\
\hline $2^{\text {nd }}$ week postoperative & $48.2 \pm 17.65$ & 5.40 & $0.001^{* *}$ \\
\hline $3^{\text {rd }}$ week post operative & $44.54 \pm 8.32$ & 4.83 & $0.001^{* *}$ \\
\hline
\end{tabular}

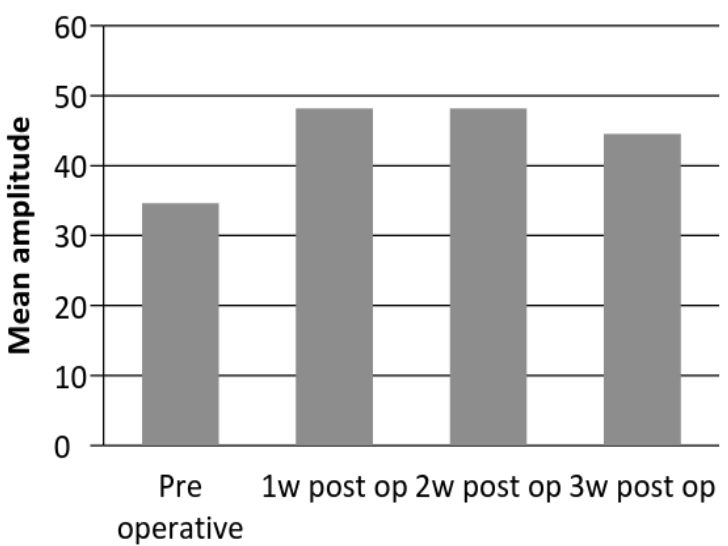

Figure 4: Diagrammatic representation of preoperative and postoperative $\mathrm{P}$ wave amplitude.

Table 6 compares the preoperative and postoperative follow ups at $1^{\text {st }}, 2^{\text {nd }}, 3^{\text {rd }}$ weeks of P wave implicit time, it showed a statistically significant improvement $P$ value $=0.047$.

Table 6: Differences between preoperative and postoperative $\mathrm{P}$ wave implicit time.

\begin{tabular}{|c|c|c|c|}
\hline Implicit time & $\begin{array}{c}\text { mean } \pm \text { SD } \\
(\mathrm{ms})\end{array}$ & $\begin{array}{c}\text { Paired t } \\
\text { test }\end{array}$ & P value \\
\hline Pre-operative & $40.88 \pm 9.17$ & & \\
\hline $1^{\text {st }}$ week post operative & $43.04 \pm 6.97$ & 2.350 & $0.03^{*}$ \\
\hline $2^{\text {nd }}$ week post operative & $40.14 \pm 4.79$ & 0.245 & 0.809 \\
\hline $3^{\text {rd }}$ week post operative & $30.48 \pm 14.55$ & 2.120 & $0.047^{*}$ \\
\hline
\end{tabular}

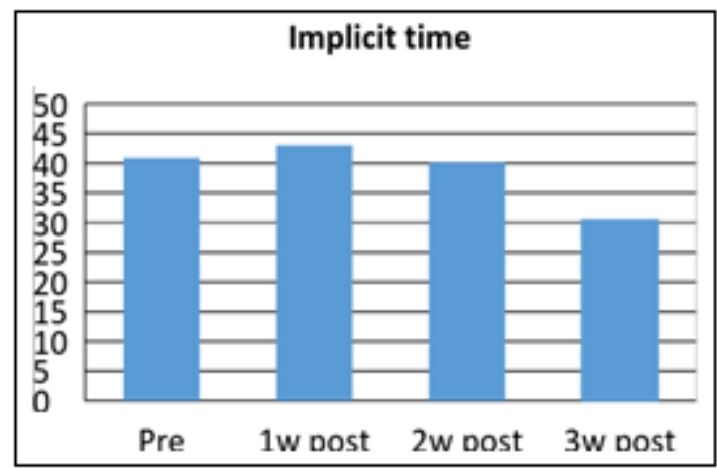

Figure 5: Diagrammatic representation between preoperative and postoperative $\mathrm{P}$ wave implicit time.

Comparison of $\mathrm{N}$ wave amplitude between preoperative and postoperative follow up periods was shown in (Table 7), there was a high significance difference $\mathrm{P}<0.001$.

Table 7: Difference between preoperative and postoperative $\mathrm{N}$ wave amplitude

\begin{tabular}{|c|c|c|c|}
\hline N wave amplitude & $\begin{array}{c}\text { mean } \pm \text { SD } \\
\mathrm{nV} / \mathrm{deg} 2\end{array}$ & $\begin{array}{c}\text { Paired } \\
\mathrm{t} \text { test }\end{array}$ & P value \\
\hline Preoperative & $0.135 \pm 0.06$ & & \\
\hline $1^{\text {st }}$ week post operative & $0.310 \pm 0.11$ & 4.88 & $0.001^{* *}$ \\
\hline $2^{\text {nd }}$ week post operative & $0.317 \pm 0.14$ & 5.02 & $0.001^{* *}$ \\
\hline $3^{\text {rd }}$ week post operative & $0.299 \pm 0.16$ & 3.95 & $0.001^{* *}$ \\
\hline
\end{tabular}

$\mathrm{N}$ wave implicit time was measured, comparing the preoperative and postoperative results (Table 8).

\section{Volume 5 Issue 7, July 2016 www.ijsr.net}




\section{International Journal of Science and Research (IJSR) \\ ISSN (Online): 2319-7064 \\ Index Copernicus Value (2013): 6.14 | Impact Factor (2015): 6.391}

Table 8: Difference between preoperative and postoperative $\mathrm{N}$ wave implicit time

\begin{tabular}{|c|c|c|c|}
\hline N wave implicit time & $\begin{array}{c}\text { mean } \pm \text { SD } \\
\mathrm{ms}\end{array}$ & $\begin{array}{c}\text { Paired } \\
\text { t test }\end{array}$ & P value \\
\hline Preoperative & $21.66 \pm 15.00$ & & \\
\hline $1^{\text {st }}$ week post-operative & $20.64 \pm 7.09$ & 0.556 & 0.584 \\
\hline $2^{\text {nd }}$ week post operative & $37.00 \pm 18.67$ & 2.410 & $0.026^{*}$ \\
\hline $3^{\text {rd }}$ week post operative & $29.3 \pm 24.85$ & 0.966 & 0.346 \\
\hline
\end{tabular}

\section{Discussion}

Many studies evaluated IVB in treatment of DME using MfERG. In our study BCVA showed improvement from $(0.37 \pm 0.23)$ preoperative to $(0.42 \pm 0.29)$ in the $3^{\text {rd }}$ week, $25 \%$ of the patients reported improvement in near vision. Measuring CMT using OCT showed statistically significant improvement $\mathrm{P}<0.001$. Central macular OCT thickness decreased from $(375.80 \pm 14.48 \mu \mathrm{m})$ preoperative to $(225.00 \pm 30.08 \mu \mathrm{m})$ postoperative and parafoveal and perifovael thickness decreased from $(317.00 \pm 36.2 \mu \mathrm{m})$ preoperative to $(282.80 \pm 27.97 \mu \mathrm{m})$ postoperative. There was a little rise of IOP after $1^{\text {st }}$ week with highly significant difference $\mathrm{P}$ value $<0.006$. It returned back to the preoperative level on the $3^{\text {rd }}$ week. In Mf-ERG , P wave amplitude improved from (34.64 \pm 9.62$) \mathrm{nv} / \mathrm{deg} 2$ preoperative to $(44.54 \pm 8.32 \mathrm{nV} / \mathrm{deg} 2)$ in $3^{\text {rd }}$ week postoperative with highly significant difference $\mathrm{P}<0.001$, $\mathrm{N}$ wave amplitude improved from $(0.135 \pm 0.060 \mathrm{nV} / \mathrm{deg} 2)$ preoperative to $(0.310 \pm 0.110 \mathrm{nV} / \mathrm{deg} 2)$ in $1^{\text {st }}$ week postoperative, $(0.317 \pm 0.140 \mathrm{nV} / \mathrm{deg} 2)$ in $2^{\text {nd }}$ week postoperative, while decreased in $3^{\text {rd }}$ week postoperative $(0.299 \pm 0.160 \mathrm{nV} / \mathrm{deg} 2)$ but remained higher than preoperative, while $\mathrm{P}$ wave implicit time improved significantly from $(40.88 \pm 9.17)$ preoperative to $(30.48 \pm 14.55)$ in the $3^{\text {rd }}$ week, $\mathrm{P}$ value $=0.047, \mathrm{~N}$ wave implicit time showed no significant difference.

Durukan et al.in 2009, found that Mf-ERG cannot be performed to evaluate retinal functionality after the treatment of DME with intravitreal injections of triamcinolone acetonide, probably because of their irreversible macular damage. ${ }^{(5)}$

Abdollahi in 2010 studied sixty-four eyes of thirty-two patients with bilateral symmetric clinically significant macular edema (CSME). After 7 days, $1.25 \mathrm{mg}$ of bevacizumab was randomly injected in one eye of each patient and the other eye was assigned for sham injection. Mf-ERG was repeated 8 weeks after injection, and changes in visual acuity and Mf-ERG were compared in two groups. The mean BCVA at baseline was 0.55 in IVB group and 0.51 in control group. At 8 th week BCVA was 0.41 and 0.53 respectively, also the $\mathrm{P}$ wave amplitude and implicit time showed significant improvement in Mf-ERG and significant improvement compared with the sham group. They concluded that IVB injection can augment the effect of macular photocoagulation (MPC) in DME and can be used as an adjunctive treatment in these cases. ${ }^{(6)}$

On the other hand, Du et al. in 2011 had documented a reduction in the amplitude of $\mathrm{P} 1$ wave after a treatment with laser photocoagulation and Leozappa et al.in had evaluated the Mf-ERG 1 week and 1, 3, and 6 months after surgery (standard three-port pars plana vitrectomy with peeling of inner limiting membrane) in 25 eyes of 21 patients with DME: both researches had considered Mf-ERG useful for predicting functional prognosis. ${ }^{(7)(8)}$

Torres- Soriano and associates in 2012 treated thirty-one eyes of thirty-one patients in their study with intravitreal injection of $0.1 \mathrm{~mL}(2.5 \mathrm{mg})$ of bevacizumab and found that subjects undergoing MF-ERG testing had no statistically significant changes in electrophysiologic responses 1 month after the IVB and that multifocal electrophysiologic testing did not demonstrate any short-term cone photoreceptor toxicity after IVB. ${ }^{(9)}$

Nepomuceno and others in 2013, concluded that IVB and IV ranibizumab are associated with similar effects on central subfoveal thickness in patients with DME through 1 year of follow up although IV ranibizumab was associated with greater improvement in BCVA at some study visits, and the mean number of injections was higher in the IVB group. ${ }^{(10)}$

In Bin $\mathrm{Wu}$ and others study in 2014, Nine independent randomised-controlled clinical trials (RCTs) involving 2,289 participants were identified, compared with bevacizumab, the overall combined weighted mean difference (WMD) of the mean change in visual acuity for ranibizumab was 0.52 letters . The risk of serious systemic events increased by $17 \%, \mathrm{P}=0.0042$ for bevacizumab treatment in comparison with ranibizumab. No statistically significant differences between the two treatments were found for the ocular serious adverse, death from vascular and all causes events, they concluded that bevacizumab was not inferior to ranibizumab as a treatment for achieving visual acuity and that the use of bevacizumab was associated with an increased risk of developing serious systemic events. ${ }^{(11)}$

Enany in 2015, evaluated MF-ERG changes in 60 eyes of 45 diabetic patients who had CSME after treatment with IVB with or without corticosteroids, patients were divided into three groups and each group included 20 eyes. The first group was treated with IVB injection alone, the second group was treated with IVB and triamcinolone injection, and the third group was treated with IVB and dexamethasone. The follow up was carried out up to 3 months. Results was that the mean visual acuity improved in the three groups, and the mean foveal thickness was reduced in the three groups. As regards Mf-ERG, P1 amplitudes were increased and P1 peak time (ms) was shortened in the three groups and concluded that diabetic macular edema can be treated with bevacizumab alone, as the use of adjuvant corticosteroids had many complications. ${ }^{(12)}$

In our study, there was a little rise of IOP after $1^{\text {st }}$ week with highly significant difference but no other adverse events including endophthalmitis, inflammation, thromboembolic events, cataract formation or progression, and retinal detachment. However, this study showed limitation as the follow up was relatively short and the number of eyes was small, features that precluded any estimation of the long term efficacy and safety of IVB.

\section{Volume 5 Issue 7, July 2016 www.ijsr.net}




\section{International Journal of Science and Research (IJSR) \\ ISSN (Online): 2319-7064}

Index Copernicus Value (2013): 6.14 | Impact Factor (2015): 6.391

\section{Conclusion}

Intravitreal Bevacizumab resulted in improvement of macular function in the study patients with diabetic macular edema, postoperative improvement in visual acuity was accompanied by decreased retinal thickness measured by OCT and improvement of $\mathrm{P}$-wave and $\mathrm{N}$ wave in Mf-ERG.

\section{References}

[1] Augustin A: Upcoming therapeutic advances in diabetic macular edema: An intravitreal dexamethasone drug delivery system. Expert opinion on drug delivery 2011; $8(2): 271-279$.

[2] Cohen AI: The retina. In Hart MJ Jr, editor: Adleres physiology of the Eye, 9th Ed, St Louis, 1992, Mosby, p 579.

[3] Diabetic Retinopathy Clinical Research Network: Three-Year Follow-up of a randomized trial comparing focal/grid photocoagulation and intravitreal triamcinolone for diabetic macular edema. Arch Ophthalmol, 2009; 127:245-251.

[4] Pescosolido N, Barbato A, Stefanucci A, and Buomprisco G: Role of electrophysiology in the early diagnosis and follow-Up of diabetic retinopathy .Journal of Diabetes Research, 2015; 3-4.

[5] Durukan A.H., Memisoglu S., and Gundogan F.C., "Is multifocal ERG a reliable index of macular function after triamcinolone acetonide injection in diffuse diabetic macular edema?" European Journal of Ophthalmology. 2009; 19(6):1017-1027.

[6] Abdollahi A, Movassat M, Ahmadabadi M, Abdollahi M ,Bashiri A: Multifocal electroretinography assisted comparison of macular photocoagulation versus macular photocoagulation and intravitreal bevacizumab injection in diabetic macular edema .Iranian Journal of Ophthalmology ,2010;22(3):23-28.

[7] Du B., Zhang H., Chan H.H.L., Wang J.T., Ho P.W. C., And $\mathrm{Xu} \mathrm{Y}$. Z., "Retinal function and morphology of severe non-proliferative diabetic retinopathy before and after retinal photocoagulation," Clinical and Experimental Optometry, 2011; 94 (3): 284-290.

[8] Leozappa M., Ferrari T.M., Grossi T.et al., "Prognostic prediction ability of postoperative multifocal ERG after vitrectomy for diabetic macular edema," European Journal of Ophthalmology, 2008; 18(4):609-613.

[9] Torres-soriano M, Lorenzo V, Aguirre G, Ndez -Rogas M. , Konawa V, Azrubio J, Guerra J, Mercado H., Nezsierra J.: Multifocal electrophysiologic findings after intravitrael bevacizumab (Avastin) treatment. The journal of retinal and vitreous diseases, 2012; 32 (5): 972-976.

[10] Nepomuceno A , Takaki E, Almeida F. , Peroni R. , Cardillo A, Siqueira R, Scott N, Messias A., Jorge R: A Prospective randomized trial of intravitreal bevacizumab versus ranibizumab for the management of diabetic macular edema .Am J Ophthalmol, 2013;156: 502-510.

[11] Wu B, Wu H, Liu X, Lin H, and Li J: Ranibizumab versus bevacizumab for ophthalmic diseases related to neovascularization: A meta-analysis of randomized controlled trials. PLOS ONE, 2014; 9(7):6-7.
[12] Enany H.: Evaluation of intravitreal corticosteroids as an adjuvant to bevacizumab for diabetic macular edema using electroretinogram. Delta Journal of Ophthalmology; 2015, 16:27-31. 